\title{
Punctal stenosis: definition, diagnosis, and treatment
}

This article was published in the following Dove Press journal:

Clinical Ophthalmology

2 July 2012

Number of times this article has been viewed

\section{Uri Soiberman' \\ Hirohiko Kakizaki² \\ Dinesh Selva ${ }^{3}$ \\ Igal Leibovitch' \\ 'Division of Oculoplastic and Orbital Surgery, Department of Ophthalmology, Tel-Aviv Medical Center, Tel-Aviv University, Tel-Aviv, Israel; ${ }^{2}$ Department of Ophthalmology, Aichi Medical University, Nagakute, Japan; ${ }^{3}$ South Australian Institute of Ophthalmology and Discipline of Ophthalmology and Visual Sciences, University of Adelaide, South \\ Australia, Australia}

Correspondence: Uri Soiberman Division of Oculoplastic and Orbital Surgery, Department of Ophthalmology, Tel-Aviv Medical Center, 6 Weizman Street, Tel-Aviv 64239, Israel

Tel +972 36973408

Fax +97236973870

Email urisoib@gmail.com
Abstract: Acquired punctal stenosis is a condition in which the external opening of the lacrimal canaliculus is narrowed or occluded. This condition is a rare cause of symptomatic epiphora, but its incidence may be higher in patients with chronic blepharitis, in those treated with various topical medications, including antihypertensive agents, and especially in patients treated with taxanes for cancer. The purpose of this review is to cover the medical literature, focusing in particular on definition, incidence, risk factors, etiology and treatment options.

Keywords: acquired punctal stenosis, definition, epiphora, etiology, treatment

\section{Introduction}

Epiphora is a common complaint encountered by ophthalmologists, with a broad differential diagnosis. One of the least discussed etiologies of epiphora is stenosis of the external lacrimal punctum. When it occurs, the most common presenting symptom is tearing, but patients may have vague complaints of ocular discomfort. ${ }^{1}$ Stenosis must be distinguished from complete occlusion of the puncti, which differs in its treatment and prognosis. This review relates only to punctal stenosis.

Anatomically, acquired punctal stenosis is a condition in which the external opening of the lacrimal canaliculus, located in the nasal part of the palpebral margin, is narrowed or occluded. A complete congenital occlusion of the external punctum is referred to as punctal agenesis. Stenosis of the external lacrimal punctum may be accompanied by canalicular or common canalicular duct stenosis, either of which may make treatment more complicated. ${ }^{2}$ The goal of this work is to review the medical literature and to highlight some of the controversial issues pertaining to punctal stenosis.

\section{Anatomy}

The lacrimal puncti are positioned at the medial part of the eyelid margins (Figure 1). They open into the tear lake near the plica semilunaris and the bulbar conjunctiva. The upper punctum is generally located $0.5-1 \mathrm{~mm}$ medial to the lower punctum according to the laterally sloped caruncle shape. When the eyelids are closed, these two puncti are usually adjacent to one another.

The puncti are located within an elevated structure referred to as the lacrimal papilla. They are considered to be $0.2-0.3 \mathrm{~mm}$ in diameter and are surrounded by a fibrous ring. ${ }^{3}$ The papillae are surrounded by the muscle of Riolan, and are pulled medially and posteriorly by the muscle fibers. ${ }^{4}$ 


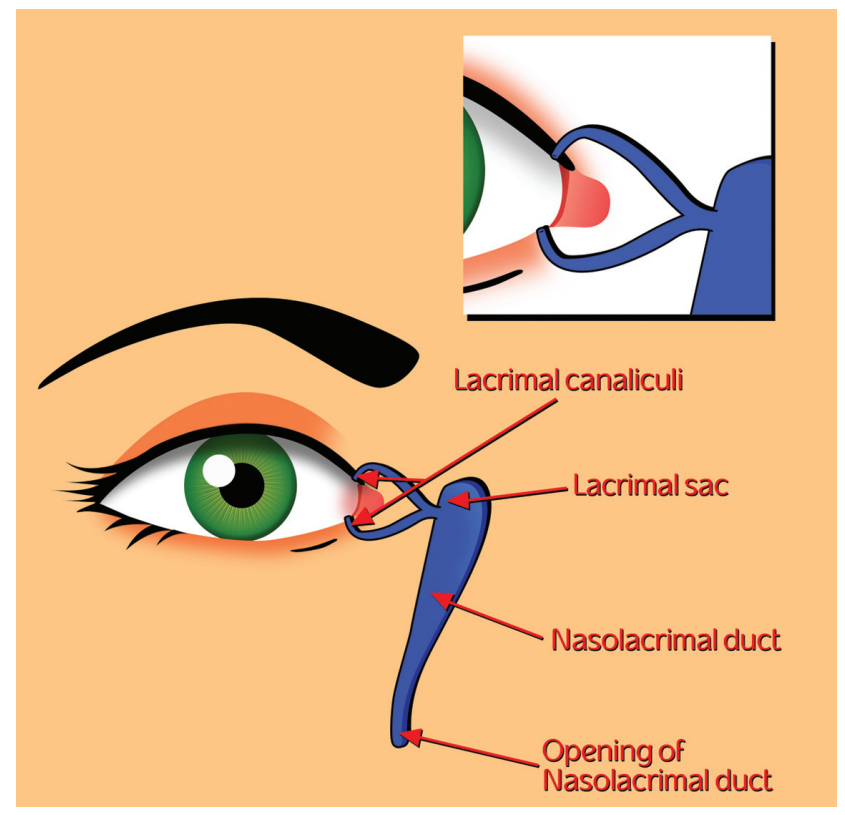

Figure I The puncti are positioned medially, near the medial canthus. They are located within the papillae. This complex opens into the tear layer. The tears are collected through the puncti and into the canaliculi.

\section{Definition}

The normal anatomy of the punctum varies greatly and there is scant evidence to aid in the clinical definition of what constitutes punctal stenosis. Textbook parameters for punctal diameter range from $0.2 \mathrm{~mm}$ to $0.5 \mathrm{~mm} .^{3,5-7}$ A prospective study of 50 asymptomatic patients found the lower puncti to be significantly larger in diameter than the upper puncti. ${ }^{8}$ No difference between genders was found. The mean area of the upper puncti was $0.264 \pm 0.141 \mathrm{~mm}^{2}$. The mean area of the lower puncti was $0.321 \pm 0.155 \mathrm{~mm}^{2}$, and the variation was substantial $\left(0.1-0.7 \mathrm{~mm}^{2}\right.$ for the upper puncti and $0.1-0.8 \mathrm{~mm}^{2}$ for the lower puncti). Unfortunately, this study utilized methods that may be more suitable for research rather than in the clinical setting, and did not assess the correlation between aperture size and clinical epiphora.

In a prospective study of about 150 patients, the mean diameter and area of lower puncti were assessed. ${ }^{9}$ The mean diameter of round-shaped puncti was $0.1 \mathrm{~mm}$, with no gender variation. The mean area was $0.008 \mathrm{~mm}^{2}$ in females and $0.01 \mathrm{~mm}^{2}$ in males (statistically insignificant). The substantial discrepancy between this measurement and that of the previous study may be explained by a change in assessment modality, ie, the previous study used photography and software analysis, while in the latter, punctal size was assessed directly by an observer using a graduated eyepiece. The latter study found a statistically significant negative relationship between punctal diameter and age in females, and demonstrated that patients with closed puncti are older than patients with open puncti $(P<0.0001)$. However, the study failed to examine the correlation between epiphora and punctal size.

Other authors define punctal stenosis as a diameter of less than $0.3 \mathrm{~mm}$ or the inability to intubate the punctum with a $26 \mathrm{G}$ cannula (outer diameter $0.47 \mathrm{~mm}$ ) without dilation. ${ }^{10}$

No randomized, controlled studies have been published on the correlation between clinical epiphora and punctal size, and so defining a clear cut-off value for punctal stenosis is difficult. Consequently, there are no uniform guidelines defining what constitutes an indication to treat punctal narrowing. The lack of consensus results in nonstandardized clinical trials and may affect the clinical decision-making process.

\section{Measurement of punctal size}

Several methodologies have been used to measure punctal size. One method entails photographing all four puncta by slit-lamp biomicroscopy. ${ }^{8}$ The punctal borders are later mapped out using a computer cursor assembly probe and a Hi Pad digitalizer. Punctal area is determined by softwaredriven computer analysis.

Another method entails use of a Ramsden eyepiece which consists of a fixed transparent graduated scale positioned on the field and fitted to the slit-lamp. ${ }^{9}$ The fixed optical magnification of $32 \times$ results in a scale resolution of $0.03 \mathrm{~mm}$.

Further potential methods may entail fitting different gauge cannulae (20-32 G), but because the punctal walls are stretched during intubation, this may not be a good predictor of punctal size under normal physiological conditions.

The method used by the authors combines both slit-lamp examination to measure punctal size coupled with microruler standardized photography of the puncti, allowing objective measurement of shape, maximal height, maximal width, and mean cross-sectional area.

\section{Incidence}

The incidence of punctal stenosis has not been determined in any large population-based studies, and the available numbers from relatively small studies vary greatly. In a retrospective chart review at a tertiary referral center in Canada, 8\% of tearing patients had either punctal stenosis or canalicular block. ${ }^{11}$ Indeed, this study was limited by its retrospective nature, its small size $(\mathrm{n}=150)$, and lack of a standardized definition of punctal stenosis. Having been conducted in a tertiary center, it was also possibly biased. Nevertheless, it reported a surprisingly high rate of punctal stenosis compared with what was believed in the past. 
In a prospective study, 682 patients (not necessarily symptomatic) referred to a general ophthalmology clinic were evaluated for punctal stenosis, defined as a punctum visible but smaller than $0.3 \mathrm{~mm}$ and requiring probing with a punctal finder, followed by a standard punctal dilator, in order to insert a 00 Bowman probe. ${ }^{12}$ Some $54.3 \%$ of the patients were diagnosed with punctal stenosis. Upper punctal stenosis was more common than lower punctal stenosis. The strength of this study lies in its relatively large population size and its observational nature, following both symptomatic and asymptomatic patients. In another study by Kashkouli et al, lower punctal stenosis was more common than upper punctal stenosis. ${ }^{1}$

None of the above-mentioned studies addressed the issue of the predictive value of epiphora in diagnosing acquired punctal stenosis. Therefore, the incidence and prevalence of punctal stenosis have yet to be determined, and it is also unclear whether a complaint of tearing warrants a meticulous search for the condition.

In summary, the incidence of punctal stenosis is still unknown, with reported rates ranging from $8 \%$ to $54.3 \%$, depending on setting, demographics, and probably interobserver variability. Nevertheless, the literature suggests that this pathology should be given special consideration while assessing the tearing patient, because it may involve an easier surgical solution than in patients with obstruction in the more distal lacrimal system.

\section{Risk factors}

Differentiating between risk factors and etiological factors in this disease is difficult. However, in a prospective study by Kashkouli et al old age and female gender were found to be risk factors. ${ }^{1}$ In other prospective studies, age was regarded as a risk factor, but there was no gender predilection. ${ }^{8,12}$ Chronic blepharitis, apart from its etiological contribution, was found to be a risk factor for recurrent stenosis after wedge punctoplasty. ${ }^{13}$

\section{Etiology}

Many factors have been implicated in the pathogenesis of acquired external punctal stenosis (see Table 1). Old age has been identified in several studies as a cause of punctal stenosis. ${ }^{1,8,14}$ The supposed pathogenesis is involutional changes involving the external lacrimal punctum leading to its narrowing or occlusion. In one study, the mean age at diagnosis was 69.4 years. ${ }^{1}$

Chronic lid inflammation, especially chronic blepharitis, remains a widely identified cause of acquired punctal stenosis. ${ }^{1,12}$
The pathogenesis suggested is chronic inflammation of the external punctum leading to gradual fibrotic changes in the ostium, followed by progressive occlusion of the duct. Dry eye syndrome, which may be secondary to chronic blepharitis, has also been suggested as an etiological factor. ${ }^{12}$ Infections involving the eyelid, such as trachoma and herpes simplex, may also result in stenosis. ${ }^{15,16}$ Other pathogens implicated are chlamydia, actinomyces, and human papilloma virus. ${ }^{10}$

Longstanding treatment with several topical antiglaucoma agents, such as timolol, latanoprost, betaxolol, dipivefrin

Table I Etiology of acquired punctal stenosis

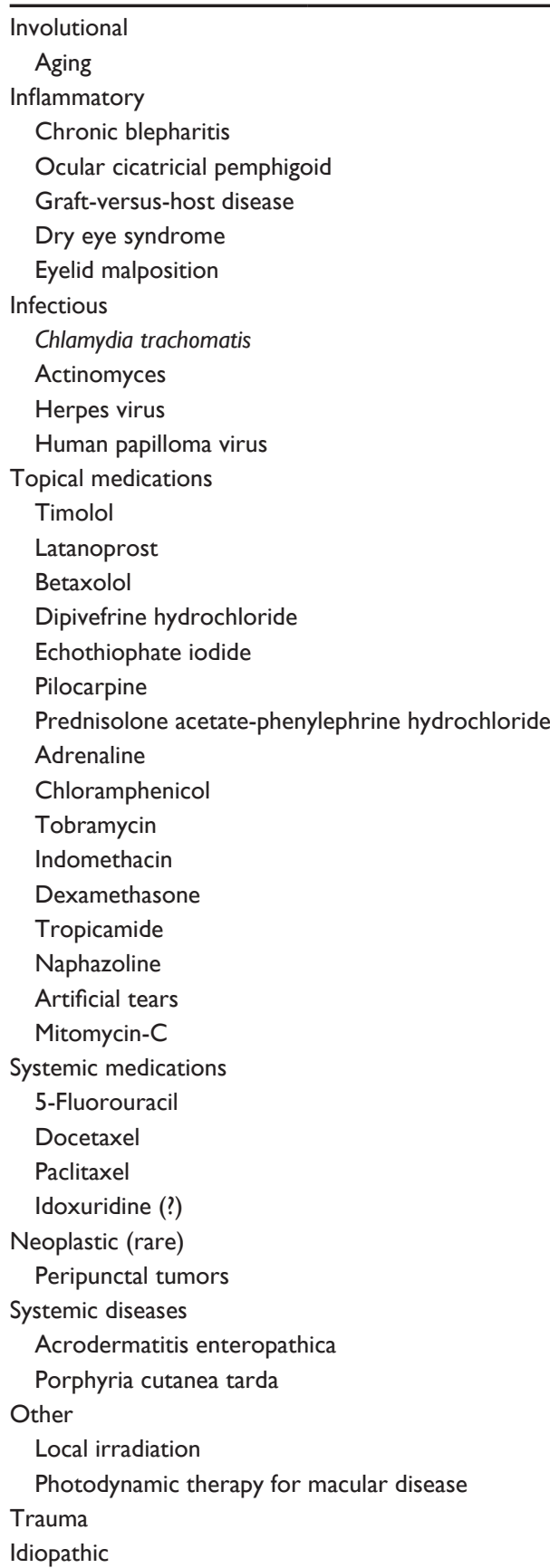

Aging

nflammatory

Dry eye syndrome

fectious

Chlamydia trachomatis

Actinomyces

Herpes virus

papilloma virus

opical medications

Timolol

Latanoprost

Dipivefrine hydrochloride

Echothiophate iodide

Pilocarpine

Adrenaline

Chloramphenico

Tobramycin

Naphazoline

Artificial tears

5-Fluorouracil

Docetaxe

clitax

oplastic (rare)

Peripunctal tumors

Other

Idiopathic 
hydrochloride, echothiophate iodide, and pilocarpine has also been associated with punctal stenosis. ${ }^{1,17}$ Other topical agents have also been suggested as causes, and are often administered simultaneously. They include prednisolone acetate/ phenylephrine hydrochloride, adrenaline, chloramphenicol, tobramycin, indomethacin, dexamethasone, tropicamide, naphazoline, and various artificial tear preparations. ${ }^{17}$ Topical administration of mitomycin $\mathrm{C}$ for ocular surface neoplasia has also been associated with punctal stenosis, but on the other hand, it has been suggested as a beneficial adjunct to corrective posterior punctectomy. ${ }^{18-20}$

Systemic medications are also associated with acquired punctal stenosis. Chemotherapeutic agents such as 5-fluorouracil, docetaxel, and paclitaxel have been implicated in the literature. ${ }^{21-27}$ Idoxuridine is also suspected to be a causative agent. ${ }^{28}$

Eyelid malposition, as seen in ectropion, may cause punctal stenosis, possibly due to underuse of an external punctum unopposed to the tear meniscus, or perhaps secondary to local inflammation. ${ }^{1,29}$ Other rare etiologies include peripunctal tumors, which are seldom observed in clinical practice. ${ }^{30}$ Systemic diseases, such as acrodermatitis enteropathica and porphyria cutanea tarda, have also been reported in association with punctal stenosis. ${ }^{10,31}$ Instances of the condition following local irradiation or photodynamic therapy for macular disease have also been described in the literature. ${ }^{10,32}$ Ocular cicatricial pemphigoid and graft-versus-host disease are further possible etiologies. Eyelid trauma and secondary healing could potentially result in stenosis as well. ${ }^{10}$

\section{Treatment}

In general, a few methods are currently used in the management of punctal stenosis. The most simple method involves use of perforated punctal plugs, which is a reversible procedure. Minor surgical techniques require incision of the puncta and punctoplasty.

\section{Perforated punctal plugs}

This procedure is an easily performed intervention, suitable for an office setting, in which a perforated punctal plug is placed in the external punctum, usually after dilation, and left in place for a certain period of time. The underlying rationale is longstanding dilation of the punctum, in order to prevent the risk of recurrent stenosis that may occur as a result of wound healing after punctal snip procedures. However, evidence for the efficacy of the procedure is scarce.

In a retrospective series of 44 eyes from 26 patients treated with dilation and the placement of a perforated punctal plug for acquired punctal stenosis, the success rate was $84.1 \%$ (37 of 44 eyes) for cessation of epiphora. ${ }^{33}$ The plugs were extracted after 2 months. Most cases had partial punctal stenosis. Associated eyelid laxity was detected in 14 eyes, and eight of them underwent a lateral tarsal strip procedure prior to plug implantation. The mean follow-up period was 19 months. Failures were due to either restenosis or horizontal eyelid laxity.

Although perforated punctal plugs are an attractive nonsurgical tool in the management of acquired punctal stenosis, the long-term results of the procedure and its role in treating punctal stenosis will have to be determined in future, larger clinical trials.

\section{Other stenting procedures}

Recent reports have suggested utilizing a mini-Monoka ${ }^{\circledR}$ stent (FCI Ophthalmics, Issy-Les-Moulineaux, France) in cases of punctal stenosis. This procedure may be more suitable for cases of combined punctal and canalicular stenosis. Prior to stent placement, dilation alone is performed, rather than a one-snip punctoplasty, followed by stenting. This method has been shown to reduce the rate of stent migration. ${ }^{34}$ Another retrospective study of 123 eyes, $73 \%$ with punctal stenosis, $72 \%$ with canalicular stenosis, and $46 \%$ with a combination of the two, has demonstrated a significant improvement of symptoms in $82 \%$ of eyes undergoing miniMonoka punctocanaliculoplasty without a snip procedure. The follow-up period was 6 weeks, and so these results may not represent long-term success. ${ }^{35}$

\section{Balloon dilation}

The method of balloon dilation has been described for the treatment of common canalicular stenosis. One study found that over half of treated patients were free of symptoms at 9 months following the procedure. ${ }^{36}$ However, balloon dilation of the punctum has not been described in clinical studies. Another disadvantage associated with this method is patient discomfort. Therefore, the role of this technique in the treatment of punctal stenosis is as yet unclear.

\section{Punctal snip procedures}

One-snip punctoplasty was initially reported in 1853 by Bowman and was later described in 1873 by Arlit. ${ }^{37,38}$ The procedure facilitates tear drainage by producing a full-length incision along the canaliculus with a canaliculus knife. This procedure undoubtedly abolishes the capillary action of the canaliculus. After a century, during which the procedure was abandoned for other alternatives, it re-emerged with Jones' single vertical 
snip down the ampulla (Figure 2). ${ }^{39}$ Failure secondary to wound reapproximation was treated with dilation and a subsequent two-snip procedure, or with a punch ampullectomy. ${ }^{13,40}$

Other interventions were later proposed to reduce further the risk of reapproximation. Placing the lid under tension with a 4-0 suture and anchoring the tarsus to a sterile button was contemplated by Dolin and Hecth in $1986 .{ }^{41}$ In 1993, Lam and Tessler suggested topical instillation of mitomycin C as an adjunctive treatment. ${ }^{42}$ In 1993, Offutt and Cowen proposed a new approach in which the punctum was removed and the vertical canaliculus was externalized. ${ }^{43}$

Success rates as high as $90 \%$ with the three-snip procedure (Figure 3) were reported by Caesar and McNabb, but these results may not reflect sustained long-term success, because the duration of follow-up was not reported..$^{10}$ Additionally, the patients in that study were questioned about epiphora only one week after surgery. Some patients may experience a perioperative paradoxical epiphora immediately after the procedure due to local irritation and inflammation from the procedure itself. ${ }^{44}$ Furthermore, of 102 potential patients, almost half were excluded; 22 because of additional surgery and 16 who elected not to undergo surgery. A paucity of data exists on patient selection, especially with respect to the coexistence of lacrimal system obstruction at sites other than the punctum, coexistence of dry eye, tear hypersecretion, or lacrimal pump failure.

In a prospective randomized study by Sadiq et al, retropunctal cautery and one-snip punctoplasty were compared with syringing alone. ${ }^{45}$ Three months after treatment, the first

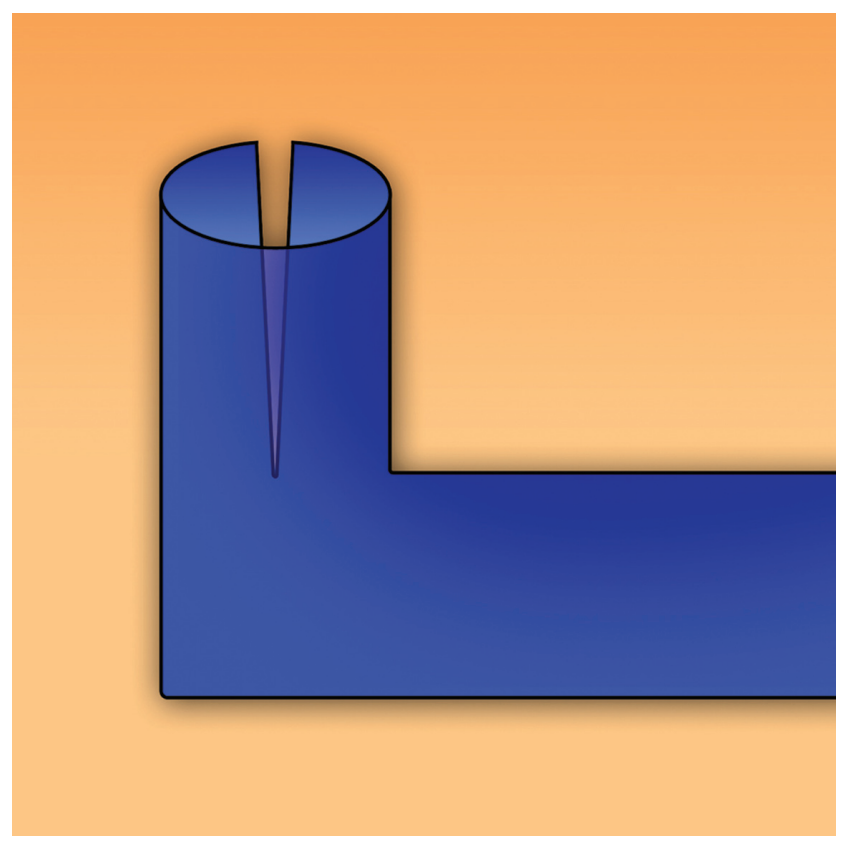

Figure 2 Jones' one-snip punctoplasty. A vertical incision is made along the ampulla.

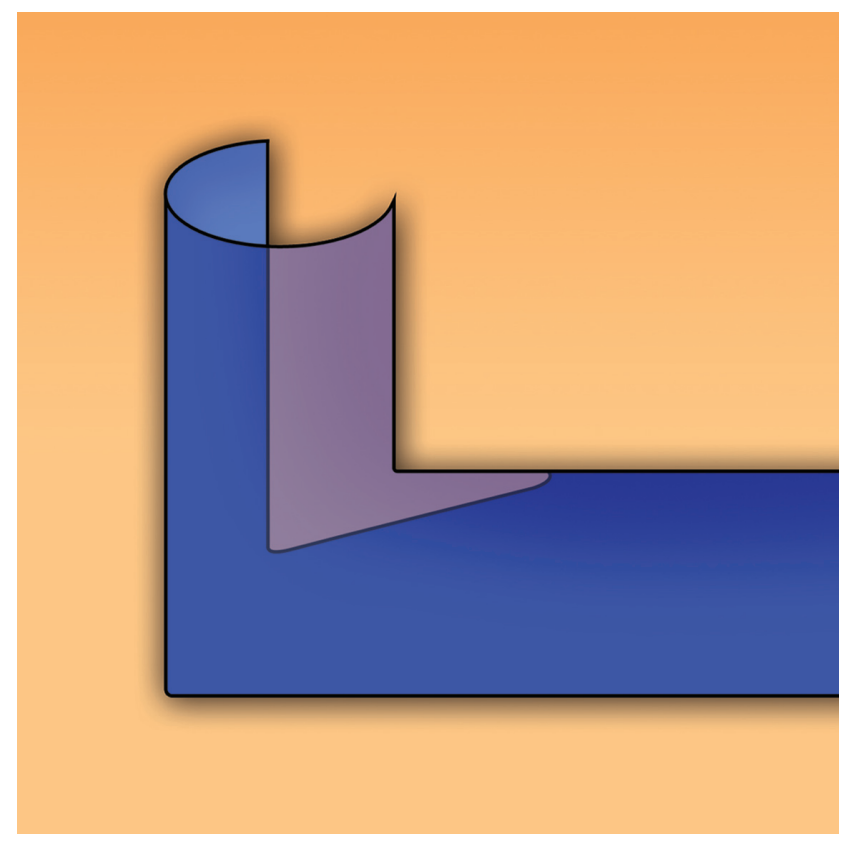

Figure 3 Three-snip punctoplasty. A vertical incision is made down the ampulla. A horizontal incision is then made along the canaliculus. A last incision made along the base of the free flap opposing the bulbar conjunctiva creates a triangular-shaped broadened punctum.

group displayed statistically significant improvement. The authors concluded that cautery and one-snip punctoplasty should be considered in patients with patent lacrimal systems and punctal stenosis. Once again, the study only provided short-term (3-month) follow-up data.

In a large retrospective study of 169 patients with appropriate preoperative evaluation, two-snip punctoplasty was compared with three-snip punctoplasty. ${ }^{46} \mathrm{~A}$ two-snip procedure entails a vertical cut to the medial and lateral wall of the punctum, followed by removal of the tissue left between the incisions. This last step is accomplished by performing a third cut at the base of the tissue bridging the cuts (Figure 4). The three-snip punctoplasty involves a vertical cut down the ampulla, followed by a horizontal cut along the roof of the canaliculus, thus forming a free flap connected to the floor of the canaliculus-ampulla complex. Subsequently, the base of the flap is incised, leaving a broadened canalicular ostium (Figure 3). In this study, 91\% of patients achieved anatomical success, while $64 \%$ achieved functional success. Partial functional success was evident in $14 \%$. Seventy-one percent of the patients were satisfied with the results. The data suggest that both two-snip and three-snip punctoplasty were satisfactory in yielding anatomical success, with $91.1 \%$ for the two-snip procedure and $94.1 \%$ for the three-snip procedure $(P=0.7)$. Accounting only for the cases with anatomical success, two-snip procedures were more likely to achieve functional success 


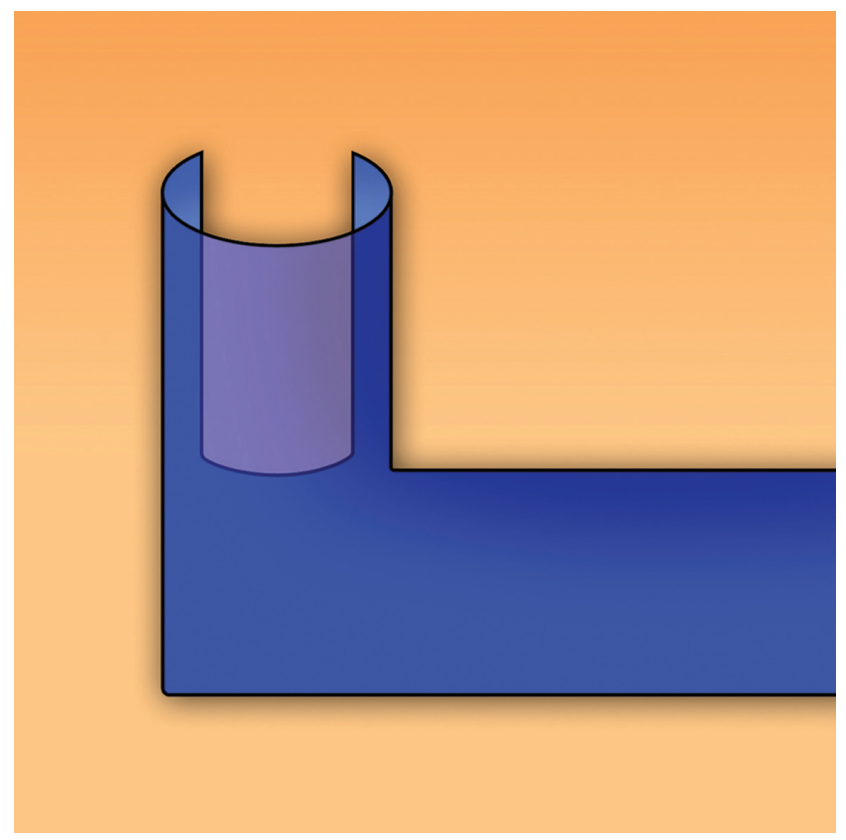

Figure 4 Two-snip punctoplasty. A vertical cut is made in the medial wall of the punctum and then in the lateral wall. The flap remaining is incised at its base.

(71.4\% versus $62.5 \%$ in the three-snip procedure, $P=0.03$ ). The surgeon grade did not seem to affect the rates of anatomical success $(P=0.4)$, making this method a suitable surgical procedure for surgeons with different skills and experience. Postoperative topical steroids did not improve surgical outcome $(P=0.7)$. The mean follow-up duration in this study was 23 (range 1-208) weeks, and so, once again, it is unclear whether the snip procedures provide long-term relief of epiphora.

Another retrospective study of 75 patients with a mean follow-up of 0.68 years suggested that rectangular punctoplasty (two vertical incisions at either side of the vertical canaliculus and one cut at the base) may be more effective than the common triangular three-snip procedure. ${ }^{47}$

Another potential problem is associated canalicular stenosis. In one study, up to $45 \%$ of patients with acquired external punctal stenosis had associated canalicular stenosis. ${ }^{1}$ This may jeopardize the results of punctoplasty alone. To address this issue, as well as the problem of punctal restenosis, a one-snip punctoplasty using mini-Monoka tube insertion was proposed. ${ }^{2}$ This procedure has yielded up to $85 \%$ functional success and $96.2 \%$ anatomical success at a mean follow-up of 18.5 months.

\section{Management of patients treated with taxanes}

Special attention must be given to patients about to undergo treatment with taxanes. In a study by Esmaeli et al it was suggested that patients treated with docetaxel be referred to an ophthalmologist as soon as they develop epiphora. ${ }^{26}$ These investigators also recommended silicone intubation and punctoplasty, depending on findings upon probing and irrigation of the canaliculi, and depending on the severity of symptoms. Punctoplasty alone was considered appropriate for patients with punctal stenosis and normal canaliculi who have already finished their treatment course with docetaxel. Bicanalicular silicone intubation was recommended for patients with canalicular stenosis and for those planning to continue on docetaxel. A later prospective study by this group examined the effect of docetaxel dosing regimens on the development of punctal stenosis. ${ }^{48}$ Epiphora developed at a mean duration of 2 months from treatment initiation in the patients treated weekly. The group treated every 3 weeks developed the condition at a mean interval of 3 months. This study has provided evidence that weekly treatment with docetaxel may be a risk factor for development of acquired punctal stenosis. Sixty-four percent of patients treated weekly developed punctal stenosis as compared with approximately $40 \%$ in the group treated every 3 weeks. That study had also suggested judicious use of topical corticosteroids, meticulous follow-up, and repeated probing and irrigation (every 4-6 weeks) as a treatment modality for a subset of patients. This regimen makes silicone intubation or other interventions redundant in $80 \%$ of the docetaxel group treated every 3 weeks and in $50 \%$ of the group treated every week. Other recommendations in patients who fail conservative therapy include long-term silicone intubation and implantation of silicone lacrimal stents to be left in position during the period of docetaxel treatment. Based on these data, we suggest screening these patients for signs of epiphora and punctal stenosis prior to treatment, and then weekly, starting two months after the initiation of treatment.

\section{Conclusion}

Punctal stenosis may in fact be a substantial etiological factor that should be considered in the assessment and treatment of the tearing patient. Lack of consensus as to what constitutes functionally disabling punctal stenosis has resulted in significant variability in the definition of the condition in research settings. Consequently, there are no uniform clinical guidelines for treatment of the disease.

The risk factors for development of acquired punctal stenosis are primarily old age and chronic blepharitis, so the main treatable risk factor is the latter, although no literature currently supports the hypothesis that treatment of chronic blepharitis reduces the incidence of acquired punctal stenosis. 
Nevertheless, considering the relative ease of managing this condition, we recommend treatment for susceptible patients, especially those with an increased risk for developing punctal stenosis due to topical or systemic treatment with causative medications.

Although perforated punctal plugs and mini-Monoka stents are theoretically promising tools in the treatment of the disease, clinical studies have yet to demonstrate their long-term success. Substantial experience with minor surgical snip procedures would suggest giving preference to their utilization in the treatment of the disease. From our experience, the one-snip procedure generally does not yield long-term success in alleviating symptoms. Therefore, we suggest performing a two-snip or three-snip punctoplasty when indicated.

\section{Disclosure}

The authors report no conflicts of interest in this work.

\section{References}

1. Kashkouli MB, Beigi B, Murthy R, Astbury N. Acquired external punctal stenosis: etiology and associated findings. Am J Ophthalmol. 2003;136(6):1079-1084.

2. Kashkouli MB, Beigi B, Astbury N. Acquired external punctal stenosis: surgical management and long-term follow-up. Orbit. 2005; 24(2):73-78.

3. Kakizaki H, Takahashi Y, Iwaki M, et al. Punctal and canalicular anatomy: implications for canalicular occlusion in severe dry eye. $\mathrm{Am}$ J Ophthalmol. 2011;153(2):229-237.

4. Olver J. Part A. Colour Atlas of Lacrimal Surgery. London, UK: Butterworth-Heinemann; 2001.

5. Ball JM. Modern Ophthalmology: A Practical Treatise on the Anatomy Physiology, and Diseases of the Eye. 5th ed. Philadelphia, PA: FA Davis; 1926.

6. Davson H. Physiology of the Eye. 4th ed. Edinburgh, UK: Churchill Livingstone; 1980.

7. Saude T. Ocular Anatomy and Physiology. Oxford, UK: Blackwell Scientific Publications; 1993.

8. Carter KD, Nelson CC, Martonyi CL. Size variation of the lacrimal punctum in adults. Ophthal Plast Reconstr Surg. 1988;4(4):231-233.

9. Patel S, Wallace I. Tear meniscus height, lower punctum lacrimale, and the tear lipid layer in normal aging. Optom Vis Sci. 2006;83(10): 731-739.

10. Caesar RH, McNab AA. A brief history of punctoplasty: the 3-snip revisited. Eye (Lond). 2005;19(1):16-18.

11. Mainville N, Jordan DR. Etiology of tearing: a retrospective analysis of referrals to a tertiary care oculoplastics practice. Ophthal Plast Reconstr Surg. 2011;27(3):155-157.

12. Bukhari A. Prevalence of punctal stenosis among ophthalmology patients. Middle East Afr J Ophthalmol. 2009;16(2):85-87.

13. Edelstein J, Reiss G. The wedge punctoplasty for treatment of punctal stenosis. Ophthalmic Surg. 1992;23(12):818-821.

14. Kristan R, Branch L. Treatment of lacrimal punctal stenosis with a one-snip canaliculotomy and temporary punctal plug. Arch Ophthalmol. 1988;106(7):878-879.

15. Tabbara KF, Bobb AA. Lacrimal system complications in trachoma. Ophthalmology. 1980;87(4):298-301.

16. Jager GV, Bijsterveld OPV. Canalicular stenosis in the course of primary herpes simplex infection. Br J Ophthalmol. 1997;81(4):332.
17. McNab AA. Lacrimal canalicular obstruction associated with topical ocular medication. Aust N Z J Ophthalmol. 1998;26(3):219-223.

18. Billing K, Karagiannis A, Selva D. Punctal-canalicular stenosis associated with mitomycin-C for corneal epithelial dysplasia. Am J Ophthalmol. 2003;136(4):746-747.

19. Khong JJ, Muecke J. Complications of mitomycin C therapy in 100 eyes with ocular surface neoplasia. Br J Ophthalmol. 2006;90(7): 819-822.

20. Ma'luf RN, Hamush NG, Awwad ST, Noureddin BN. Mitomycin C as adjunct therapy in correcting punctal stenosis. Ophthal Plast Reconstr Surg. 2002;18(4):285-288.

21. Brink HM, Beex LV. Punctal and canalicular stenosis associated with systemic fluorouracil therapy. Report of five cases and review of the literature. Doc Ophthalmol. 1995;90(1):1-6.

22. Caravella LP Jr, Burns JA, Zangmeister M. Punctal-canalicular stenosis related to systemic fluorouracil therapy. Arch Ophthalmol. 1981; 99(2):284-286.

23. Lee V, Bentley CR, Olver JM. Sclerosing canaliculitis after 5-fluorouracil breast cancer chemotherapy. Eye. 1998;12(3):343-349.

24. Eiseman AS, Flanagan JC, Brooks AB, Mitchell EP, Pemberton CH. Ocular surface, ocular adnexal, and lacrimal complications associated with the use of systemic 5-fluorouracil. Ophthal Plast Reconstr Surg. 2003;19(3):216-224.

25. Skolnick CA, Doughman DJ. Erosive conjunctivitis and punctal stenosis secondary to docetaxel (Taxotere). Eye Contact Lens. 2003;29(2): 134-135.

26. Esmaeli B, Valero V, Ahmadi MA, Booser D. Canalicular stenosis secondary to docetaxel (Taxotere): a newly recognized side effect. Ophthalmology. 2001;108(5):994-995.

27. McCartney E, Valluri S, Rushing D, Burgett R. Upper and lower system nasolacrimal duct stenosis secondary to paclitaxel. Ophthal Plast Reconstr Surg. 2007;23(2):170-171.

28. Cherry PM, Falcon MG. Punctal stenosis caused by idoxuridine or acrodermatitis enteropathica? Arch Ophthalmol. 1976;94(9):1632.

29. O'Donnell FE. Medial ectropion: association with lower lacrimal obstruction and combined management. Ophthalmic Surg. 1986;17(9): 573-576.

30. Rumelt S, Pe'er J, Rubin PA. The clinicopathological spectrum of benign peripunctal tumours. Graefes Arch Clin Exp Ophthalmol. 2005; 243(2):113-119.

31. Matta CS, Felker GV, Ide CH. Eye manifestations in acrodermatitis enteropathica. Arch Ophthalmol. 1975;93(2):140-142.

32. Yim JF, Crofts KP. Bilateral punctal-canalicular stenosis following photodynamic therapy for choroidal neovascularization. Cutan Ocul Toxicol. 2011;30(1):78-79.

33. Konuk O, Urgancioglu B, Unal M. Long-term success rate of perforated punctal plugs in the management of acquired punctal stenosis. Ophthal Plast Reconstr Surg. 2008;24(5):399-402.

34. Mathew RG, Olver JM. Mini-monoka made easy: a simple technique for mini-monoka insertion in acquired punctal stenosis. Ophthal Plast Reconstr Surg. 2011;27(4):293-294.

35. Hussain RN, Kanani H, McMullan T. Use of mini-monoka stents for punctal/canalicular stenosis. Br J Ophthalmol. 2012;96(5):671-673.

36. Lachmund U, Ammann-Rauch D, Forrer A, et al. Balloon catheter dilatation of common canaliculus stenosis. Orbit. 2005;24(3):177-183.

37. Bowman W. Treatment method applicable to epiphora dependent on the outside reversal or obliteration of the lacrimal puncti. Ann Oculist. 1853;28:52-55. French.

38. Arlit F. Surgery of the lacrimal system, In: Graefe A, Saemisch T, editors. Handbook of the entire ophthalmology. Leipzig, East Germany. Publisher: Von Wilhelm Englemann; 1874. German.

39. Jones LT. The cure of epiphora due to canalicular disorders, trauma and surgical failures on the lacrimal passages. Am Acad Ophthalmol Otolaryngol. 1962;66:506-524.

40. Hughes WI, Maris CSG. A clip procedure for stenosis and eversion of the lacrimal punctum. Trans Am Acad Ophthalmol Otolaryngol. 1967; 71(4):653-655. 
41. Dolin SI, Hecth SD. The punctum pucker procedure for stenosis of the lacrimal punctum. Arch Ophthalmol. 1986;104(7):1086-1087.

42. Lam S, Tessler HH. Mitomycin as adjunct therapy in correcting iatrogenic punctal stenosis. Ophthalmic Surg. 1993;24(2):123-124.

43. Offutt WN IV, Cowen DE. Stenotis puncta: microsurgical punctoplasty. Ophthal Plast Reconstr Surg. 1993;9(3):201-205.

44. Yuen KS, Chan DD, Chan WM, Lam DS. A brief history of punctoplasty: the 3-snip revisited. Eye (Lond). 2006;20(3):402-403.

45. Sadiq SA, Downes RN. Epiphora: a quick fix? Eye (Lond). 1998; 12(Pt 3a):417-418.
46. Shahid H, Sandhu A, Keenan T, Pearson A. Factors affecting outcome of punctoplasty surgery: a review of 205 cases. Br J Ophthalmol. 2008; 92(12):1689-1692.

47. Chak M, Irvine F. Rectangular 3-snip punctoplasty outcomes: preservation of the lacrimal pump in punctoplasty surgery. Ophthal Plast Reconstr Surg. 2009;25(2):134-135.

48. Esmaeli B, Amin S, Valero V, et al. Prospective study of incidence and severity of epiphora and canalicular stenosis in patients with metastatic breast cancer receiving docetaxel. J Clin Oncol. 2006;24(22): $3619-3622$
Clinical Ophthalmology

\section{Publish your work in this journal}

Clinical Ophthalmology is an international, peer-reviewed journal covering all subspecialties within ophthalmology. Key topics include: Optometry; Visual science; Pharmacology and drug therapy in eye diseases; Basic Sciences; Primary and Secondary eye care; Patient Safety and Quality of Care Improvements. This journal is indexed on

\section{Dovepress}

PubMed Central and CAS, and is the official journal of The Society of Clinical Ophthalmology (SCO). The manuscript management system is completely online and includes a very quick and fair peer-review system, which is all easy to use. Visit http://www.dovepress.com/ testimonials.php to read real quotes from published authors. 